\title{
The Opposite Polarity of the PQ Segment Compared to the P Wave Isointegral Maps
}

\author{
K. KOZLÍKOVÁ ${ }^{1}$, J. MARTINKA ${ }^{1}$, J. MURÍN ${ }^{2}$, J. BULAS $^{2}$ \\ ${ }^{1}$ Institute of Medical Physics, Biophysics, Informatics and Telemedicine, Faculty of Medicine, \\ Comenius University in Bratislava, Bratislava, Slovak Republic, ${ }^{2}$ The First Department of Internal \\ Medicine, Faculty of Medicine, Comenius University in Bratislava, Bratislava, Slovak Republic
}

Received November 18, 2010

Accepted June 10, 2011

On-line August 1, 2011

\section{Summary}

The aim of our work was to study the opposite polarity of the PQ segment to the $P$ wave body surface potential maps in different groups of patients. We constructed isointegral maps (IIM) in 26 healthy controls (C), 16 hypertensives (HT), 26 patients with arterial hypertension and left ventricular hypertrophy (LVH) and 15 patients with myocardial infarction (MI). We analyzed values and positions of map extrema and compared the polarity of maps using the correlation coefficient. The IIM $\mathrm{P}$ maxima appeared mainly over the precordium, the minima mainly in the right subclavicular area. The highest maxima were in the MI group, being significantly higher than in the HT and LVH groups. No differences concerning any values of other extrema were significant. The IIM PQ maxima were distributed over the upper half of the chest; the minima mainly over the middle sternum. A statistically significant opposite polarity between the IIM P and IIM PQ was found in $80 \%$ of cases. The opposite polarity of the $\mathrm{P}$ wave and the $\mathrm{PQ}$ segment was proved in isointegral body surface maps. The extrema occurred in areas not examined by the standard chest leads. This has to be considered for diagnostic purposes.

\section{Key words}

Body surface potential mapping • Atrial repolarisation • Arterial hypertension • Left ventricular hypertrophy • Myocardial infarction

\section{Corresponding author}

Katarína Kozlíková, Institute of Medical Physics, Biophysics, Informatics and Telemedicine, Faculty of Medicine, Comenius University in Bratislava, Sasinkova 2, SK-813 72 Bratislava, Slovak Republic. E-mail: katarina.kozlikova@fmed.uniba.sk

\section{Introduction}

In the standard 12-lead electrocardiogram, the atrial depolarisation is represented by the $\mathrm{P}$ wave and the atrial repolarisation occurres during the PQ segment and the QRS complex. The polarity of the atrial repolarisation wave $T_{a}$ is normally opposite to that of the $P$ wave. The potentials generated by the atrial repolarisation are difficult to study for two reasons. Firstly, their amplitude is very low, usually under $0.1 \mathrm{mV}$ and, therefore, the $\mathrm{T}_{\mathrm{a}}$ wave is very often not recorded on the standard electrocardiogram. Secondly, ventricular activation may begin before the atrial repolarisation ends; therefore, then the QRS complex overlaps it. When a positive $\mathrm{P}$ wave is recorded and a $T_{a}$ wave exists, the electrocardiographic curve between the $\mathrm{P}$ wave and the beginning of the QRS complex can be oblique. During tachycardia, the PQ segment can be even more depressed. The atrial repolarisation can be recorded even during the ST segment. Changes of the PQ segment shape were found in myocardial infarction of the right atrium. More often, a change in the PQ duration is found in preexcitation or atrioventricular conduction blockade. Therefore, correct evaluation of the PQ segment has high diagnostic importance (Cagán̆ and Hulín 1981, Mirvis 1993).

On the other side, the flat portion of the PQ segment is often taken as the zero baseline in body surface potential mapping, for example when diagnosing myocardial infarction or when the normally flat TP segment is not usable for some reason, mainly high heart rate (Takala et al. 2001, Vesterinen et al. 2004, Yamaki et al. 1988). 
Table 1. Blood pressure and selected echocardiographic characteristics of patient groups.

\begin{tabular}{lllllll}
\hline Group & $\begin{array}{c}\text { BPS } \\
{[\mathbf{m m H g}]}\end{array}$ & $\begin{array}{c}\text { BPD } \\
{[\mathbf{m m H g}]}\end{array}$ & $\begin{array}{c}\text { LVM } \\
{[\mathbf{g}]}\end{array}$ & $\begin{array}{l}\text { LVMI } \\
{\left[\mathbf{g} \cdot \mathbf{m}^{-2}\right]}\end{array}$ & RWT & $\begin{array}{c}\text { LAD } \\
{[\mathbf{m m}]}\end{array}$ \\
\hline$H T$ & $145 \pm 17$ & $93 \pm 7$ & $212 \pm 34^{\mathrm{a}}$ & $106 \pm 11^{\mathrm{a}}$ & $0.42 \pm 0.04$ & $3.7 \pm 0.4$ \\
$L V H$ & $157 \pm 22$ & $94 \pm 14$ & $317 \pm 68$ & $155 \pm 30$ & $0.49 \pm 0.08^{\mathrm{b}}$ & $4.1 \pm 0.5^{\mathrm{c}}$ \\
$M I$ & $119 \pm 12^{\mathrm{d}}$ & $79 \pm 6^{\mathrm{d}}$ & $275 \pm 83$ & $134 \pm 35$ & $0.38 \pm 0.10$ & $3.4 \pm 0.4$ \\
\hline
\end{tabular}

BPS: systolic blood pressure, BPD: diastolic blood pressure, LAD: left atrial diameter; ${ }^{a} \mathrm{p}<0.05$ group HT against groups LVH and MI, ${ }^{b} p<0.05$ group LVH against groups HT and MI, ${ }^{c} p<0.05$ group LVH against group MI, ${ }^{d} p<0.05$ group MI against groups HT and LVH

The research on body surface potential mapping deals predominantly with the ventricular excitation process. A limited number of data describing the atrial electric events is available. They are mainly devoted to isopotential maps as well as papers concerning the PQ segment mapping (Ihara et al. 2006, Kozlíková 2007, Mirvis 1980, Spach et al. 1979, Stilli et al. 1983). Only a few papers deal with body surface isointegral $\mathrm{P}$ wave maps as reviewed previously (Kozlíková 2007). No data dealing with isointegral maps during the PQ segment except for our studies have been found yet.

The limited number of data concerning body surface mapping of atrial activation may be also due to small amplitudes of the $\mathrm{P}$ waves and even smaller amplitudes of the PQ segments. Therefore, both can easily be distorted by noise. This can be at least partially avoided by using isointegral maps as they can stress small changes lasting longer time.

The aim of this retrospective study was to find out whether the opposite polarity during the PQ segment to the $\mathrm{P}$ wave can be recorded when using body surface potential mapping - isointegral maps and whether these isointegral maps differ between evaluated groups of patients.

\section{Methods}

\section{Patients and controls}

We studied isointegral maps of 83 subjects with different diagnosis. Group HT involved 16 patients (10 men, 6 women) with arterial hypertension, at age 2575 years $(50 \pm 13$ y). Arterial hypertension with left ventricular hypertrophy (group LVH) had 26 patients (15 men, 11 women), at age 32-72 years $(54 \pm 12$ y). Group MI involved 15 men, three months after acute myocardial infarction, at age 40-70 years $(53 \pm 9$ y). Control group $\mathrm{C}$ involved 26 healthy controls (16 men,
10 women), at age 21-56 years ( $33 \pm 13 \mathrm{y})$. None of the controls had any sign of cardiovascular disease; all had normal 12-lead standard electrocardiorgaphic as well as echocardiographic findings.

All examined patients were hospitalised for cardiovascular reasons. The body surface potential mapping was performed during the first days after admission; altogether in more than 90 patients. Patients with conduction disturbances, renal insufficiency and/or diabetes were excluded from this study.

The diagnosis of arterial hypertension was based on repeated clinical examinations when the systolic blood pressure was higher than $140 \mathrm{mmHg}$ and/or the diastolic blood pressure was higher than $90 \mathrm{mmHg}$; the diagnosis was established at least 5 years before admission to hospital. All patients were treated according to the guidelines with combination therapy used in most patients (Mancia et al. 2007). Hypertension was controlled near to the target blood pressure only in the HT men subgroup $(142 \pm 16 / 92 \pm 8 \mathrm{mmHg})$; it was not well controlled in the HT women subgroup nor in the whole LVH group. The values of mean blood pressure measured a few minutes before the mapping examination are given in Table 1.

The left ventricular mass LVM [g] was calculated according to the formula

$$
\mathrm{LVM}=1.04 \cdot\left[(\mathrm{IVSd}+\mathrm{LVPWd}+\mathrm{LVIDd})^{3}-\mathrm{LVIDd}^{3}\right]-13.6,
$$

where IVSd is the thickness of the interventricular septum [cm], LVPWd is the thickness of the left ventricular posterior wall [cm], LVIDd is the diameter of the left ventricle [cm], all in diastole (Bulas et al. 1998). The left ventricular hypertrophy was based on the left ventricular mass index LVMI $>109 \mathrm{~g} / \mathrm{m}^{2}$ for women and LVMI $>134 \mathrm{~g} / \mathrm{m}^{2}$ for men, where 
Table 2. Heart rate and durations of the examined intervals.

\begin{tabular}{lcccc}
\hline \multirow{2}{*}{ Group } & Heart rate $\left[\mathbf{m i n}^{-1}\right]$ & \multicolumn{3}{c}{ Duration [ms] } \\
\cline { 3 - 5 } & & P wave & PQ segment & PQ interval \\
\hline C & $60 \pm 15$ & $88 \pm 12$ & $59 \pm 18$ & $147 \pm 21$ \\
$H T$ & $68 \pm 21$ & $95 \pm 14$ & $73 \pm 28$ & $167 \pm 38$ \\
LVH & $65 \pm 26$ & $96 \pm 9^{*}$ & $72 \pm 29$ & $168 \pm 31^{*}$ \\
MI & $80 \pm 8^{*}$ & $100 \pm 14^{*}$ & $67 \pm 14$ & $167 \pm 17^{*}$ \\
Total & $67 \pm 19$ & $94 \pm 13$ & $67 \pm 24$ & $161 \pm 29$ \\
\hline
\end{tabular}

$* \mathrm{p}<0.05$ against group $\mathrm{C}$

$$
\mathrm{LVMI}=\frac{\mathrm{LVM}}{\mathrm{BSA}}
$$

Body surface area was calculated according to Mosteller formula (Mosteller 1987)

$$
\mathrm{BSA}=\sqrt{\frac{\mathrm{m} \cdot \mathrm{h}}{3600}},
$$

where $\mathrm{m}$ is the body mass $[\mathrm{kg}]$ and $\mathrm{h}$ is the body height [cm]. In the LVH group, 18 patients had concentric hypertrophy (RWT $>0.45$ ) and 8 had eccentric hypertrophy. RWT is the relative wall thickness

$$
\mathrm{RWT}=\frac{\mathrm{IVSDd}+\mathrm{LVPWd}}{\mathrm{LVIDd}} .
$$

Left atrial diameter was normal in 12/16 patients in HT group, in 13/26 patients in LVH group and in 7/15 patients in MI group. The remaining patients had the left atrium mildly or moderately abnormal (Lang et al. 2005). Right atrial diameter was normal in all subjects. Selected echocardiographic characteristics of all patients, all obtained in M-mode and measured by two investigators (co-authors), are given in Table 1.

The diagnosis myocardial infarction was based on medical history, standard electrocardiographic, on echocardiographic (ventricular wall mation) and on laboratory examinations. Seven patients had anterior and eight had inferior infarction, all of small size with preserved left ventricular function (the ejection fraction was $50-60 \%$ ). All patients underwent successful thrombolytic therapy.

\section{Body surface potential mapping}

Unipolar electrocardiograms were recorded in supine positions during normal expiration using the mapping system ProCardio with 24 leads after Barr (Barr et al. 1971, Rosík et al. 1997). A linear baseline through the TP segments before and after the analyzed heartbeat was used (Kozlíková 1990). The onset and the end of the $P$ wave and the onset of the QRS complex were established manually from the root mean square signal of the map. The limiting points were set at the end of a sequence of decreasing values when starting from the middle of the $\mathrm{P}$ wave or from the middle of the QRS complex. The PQ segment was taken as the interval between the end of the P wave and the QRS onset; the PQ interval involved both the $\mathrm{P}$ wave and the PQ segment. To ensure the reproducibility of data processing, all mapping registrations and signal processing were done by the same investigator (the author) and based on the same procedures and algorithms.

The isointegral maps (distributions of time integrals of voltage) were constructed for single beats. Then the mean maps were calculated for every subject ( $8 \pm 3$ beats depending on the heart rate) and evaluated. We analysed the values and positions of the map extrema (maximum, minimum), and the peak-to-peak amplitudes (maximum minus minimum), and compared the polarity of maps.

\section{Statistical evaluation}

To describe and to analyse the data statistically, we used averages and standard deviations. Analysis of variance with suitable post hoc tests was used to isolate differences for multiple comparisons. The polarity between pairs of maps was compared using Pearson's correlation coefficient. Each coefficient was tested whether it differs from zero to establish the statistical significance of correlation (Kozlíková and Martinka 2009). Extrema values and positions in pairs of maps were compared using paired t-test. Calculations were 
Table 3. The average values and standard deviations of the map extrema in the studied groups.

\begin{tabular}{lccc}
\hline Extreme & $\begin{array}{c}\text { Maximum } \\
{[\mathbf{m V} \cdot \mathbf{m s}]}\end{array}$ & $\begin{array}{c}\text { Minimum } \\
{[\mathbf{m V} \cdot \mathbf{m s}]}\end{array}$ & $\begin{array}{c}\text { Peak-to-peak amplitude } \\
{[\mathbf{m V} \cdot \mathbf{m s}]}\end{array}$ \\
\hline Group & & $\mathbf{P}$ wave & $8.0 \pm 2.5$ \\
$C$ & $4.0 \pm 1.1$ & $-4.0 \pm 1.5$ & $8.1 \pm 2.2$ \\
$H T$ & $3.6 \pm 0.8^{*}$ & $-4.5 \pm 1.5$ & $8.0 \pm 1.9$ \\
$L V H$ & $3.8 \pm 0.8^{*}$ & $-4.1 \pm 1.3$ & $8.0 \pm 2.5$ \\
$M I$ & $5.0 \pm 1.1$ & $-4.0 \pm 1.5$ & $2.8 \pm 1.4$ \\
\hline Group & & $\mathbf{P Q} \mathbf{s e g m e n t}$ & $3.3 \pm 1.4$ \\
$C$ & $1.0 \pm 0.7$ & $-1.7 \pm 0.7$ & $3.6 \pm 2.2$ \\
$H T$ & $1.1 \pm 0.6$ & $-2.2 \pm 1.0$ & $2.5 \pm 0.9$ \\
\hline$V H$ & $1.1 \pm 0.8$ & $-2.5 \pm 1.5$ & $-1.6 \pm 0.7$ \\
\hline
\end{tabular}

$* \mathrm{p}<0.05$ against group MI

Table 4. Correlation coefficients from the comparison of the $P$ wave and $P Q$ segment maps.

\begin{tabular}{lccc}
\hline \multirow{2}{*}{ Group } & \multicolumn{3}{c}{ Correlation coefficient } \\
\cline { 2 - 4 } & All & Only negative & Different from zero \\
\hline \multirow{2}{*}{ C } & $-0.35 \pm 0.29$ & $-0.44 \pm 0.22$ & $-0.50 \pm 0.17$ \\
& $(26 ; 100 \%)$ & $(22 ; 85 \%)$ & $(19 ; 73 \%)$ \\
$H T$ & $-0.53 \pm 0.35$ & $-0.57 \pm 0.32$ & $-0.65 \pm 0.26$ \\
& $(16 ; 100 \%)$ & $(15 ; 94 \%)$ & $(13 ; 81 \%)$ \\
LVH & $-0.46 \pm 0.27$ & $-0.53 \pm 0.19$ & $-0.53 \pm 0.19$ \\
& $(26 ; 100 \%)$ & $(23 ; 88 \%)$ & $-0.46 \pm 0.19$ \\
Total & $-0.32 \pm 0.29$ & $-0.43 \pm 0.21$ & $(11 ; 73 \%)$ \\
& $(15 ; 100 \%)$ & $(12 ; 80 \%)$ & $-0.53 \pm 0.21$ \\
& $-0.41 \pm 0.30$ & $-0.49 \pm 0.24$ & $(66 ; 80 \%)$ \\
\hline
\end{tabular}

average \pm standard deviation (number of cases; percentage)

performed using the statistical package Statgraphics Plus (Statgraphics 1997). Differences were considered as statistically significant if $\mathrm{p}<0.05$.

\section{Results}

All electrocardiographic recordings were performed during normal sinus rhythm. The heart rate was comparable in all patient groups. Significantly higher heart rate was only in the MI group against controls (Table 2). Nevertheless, the P wave and the PQ interval durations were significantly shorter in the control group than in the groups LVH and MI.
The individual single beat $P$ wave maps displayed mostly a bipolar distribution (one maximum and one minimum) resembling the pattern types described earlier (Kozlíková 2007). The single PQ segment maps were very often multipolar (3 or 4 extrema occurred), much flatter and visually often displaying the reversed polarity to the $\mathrm{P}$ wave maps. The mean maps of individual patients were smoother and their reversed polarity was visually preserved.

The group mean maps had bipolar distributions (Figure 1). The $\mathrm{P}$ wave maps displayed negativities in the upper part and positivities in the lower part of the chest. The polarity of the PQ segment maps was reversed and 


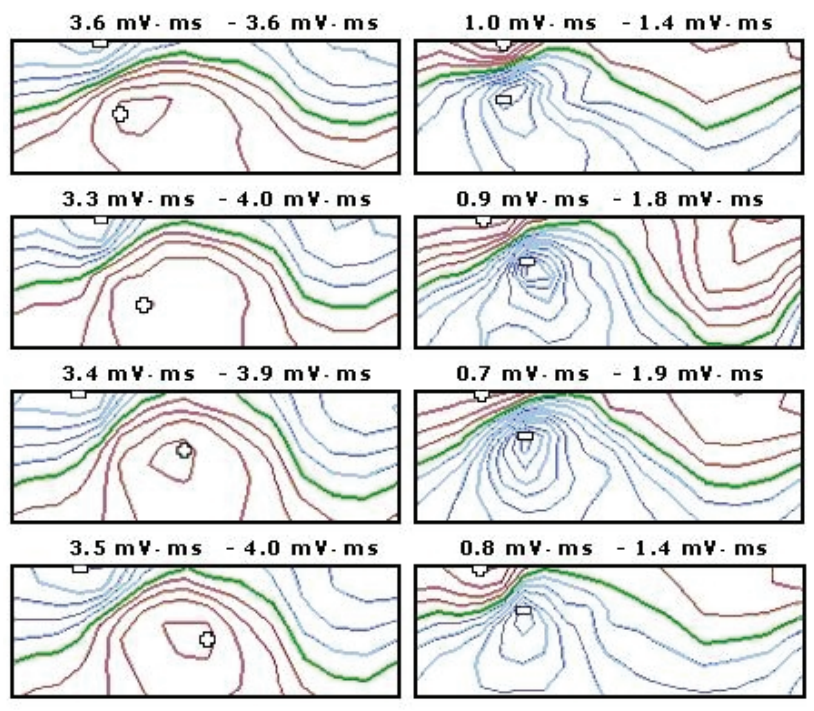

Fig. 1. The mean isointegral maps of all studied groups. The P wave maps (from top to bottom: C, HT, LVH, and MI) are in the left column (step between isointegral lines is $0.8 \mathrm{mV} \cdot \mathrm{ms}$ ) and the matching $\mathrm{PQ}$ segment maps are in the right column (step $0.2 \mathrm{mV} \cdot \mathrm{ms}$ ). The corresponding maximal and minimal values are above each map. The left half of each rectangle displays the anterior chest, the right half the back.

they were much flatter.

We found significantly higher maxima of the $\mathrm{P}$ wave in the group MI than in the groups HT and LVH. Because of multiple comparisons, differences concerning the values of next extrema were significant neither in the $\mathrm{P}$ wave maps nor in the maps of the PQ segment (Table 3). The maxima of the $P$ wave maps were located mainly in the precordial area, the minima mainly parasternally right at the clavicular level or around the right shoulder (Figure 2). Although there were some shifts in positions of both extrema between different groups, the dominating locations were close each other.

The maxima in the single beat PQ segment maps were located approximately in reversed positions compared to the $\mathrm{P}$ wave maps (Figure 2). The minima of the PQ segment maps were in average significantly closer to the sternum and shifted slightly upwards than the maxima in the $\mathrm{P}$ wave maps. The maxima of the PQ segment maps appeared almost in the same position than minima of the P wave maps, but some of them were found also on the upper half of the back.

The opposite (reversed) polarity of the atrial depolarisation and repolarisation was verified by the comparison of maps using the Pearson's correlation coefficient (Table 4). From all possible 83 comparisons, in 66 cases $(80 \%)$ was the correlation coefficient negative and significantly differed from zero. The most frequent significant negative correlations were found in the LVH group. The weakest correlation was found in the MI group. Differences between groups were not significant.

\section{Discussion}

The electrocardiographic body surface mapping is an above standard recording method that offers the most possible information about electrical activity of the heart obtained in a non-invasive way, but comparable to information available from invasive methods. The disadvantage that constrains the standard 12-lead electrocardiogram from providing a more comprehensive and transparent description of the electrical state of the heart, is the limited number of the used electrodes and the location of the chest electrodes in a small area compared to the whole chest. Although the electrodes of the unipolar leads, which are placed very close to the heart, give the best information about the events in their vicinity, this standard 6 chest electrode configuration causes that the most informative regions of the surface potential distribution, for example, local minima and maxima, are often missed by it as we found in this and previous studies. This can be critical in the case of low amplitude potentials such as the P wave or PQ segment (Ihara et al. 2006, Kornreich et al. 1989, Kozlíková 2007, Mirvis 1980, Spach et al. 1979, Stilli et al. 1983).

The duration of the $\mathrm{P}$ waves as well as of the PQ intervals in controls was shorter than in the published mapping data (Ihara et al. 2006, Kornreich et al. 1989). Nevertheless, prolonged $\mathrm{P}$ waves were found in patients with left ventricular hypertrophy against controls (Kornreich et al. 1989) and in patients with paroxysmal atrial fibrillation against controls when using high resolution electrocardiography recordings during sinus rhythm (Vranka et al. 2007). The differences concerning the controls could be due to different lead system (24 leads against 64 leads (Ihara et al. 2006) or 117 leads (Kornreich et al. 1989)) and slightly different criteria for the $\mathrm{P}$ wave onsets and ends used (established from the Frank VCG leads, not from map leads).

The duration of the $\mathrm{P}$ waves and the PQ intervals in this study was measured by applying the same method to all records. Therefore, the prolonged duration of these parts in patients can be explained neither by the higher age of the patients as was the age of the compared controls (Macfarlane and Veitch Lawrie 1989) nor by the heart rate (Table 2). It could be ascribed to dilated or 

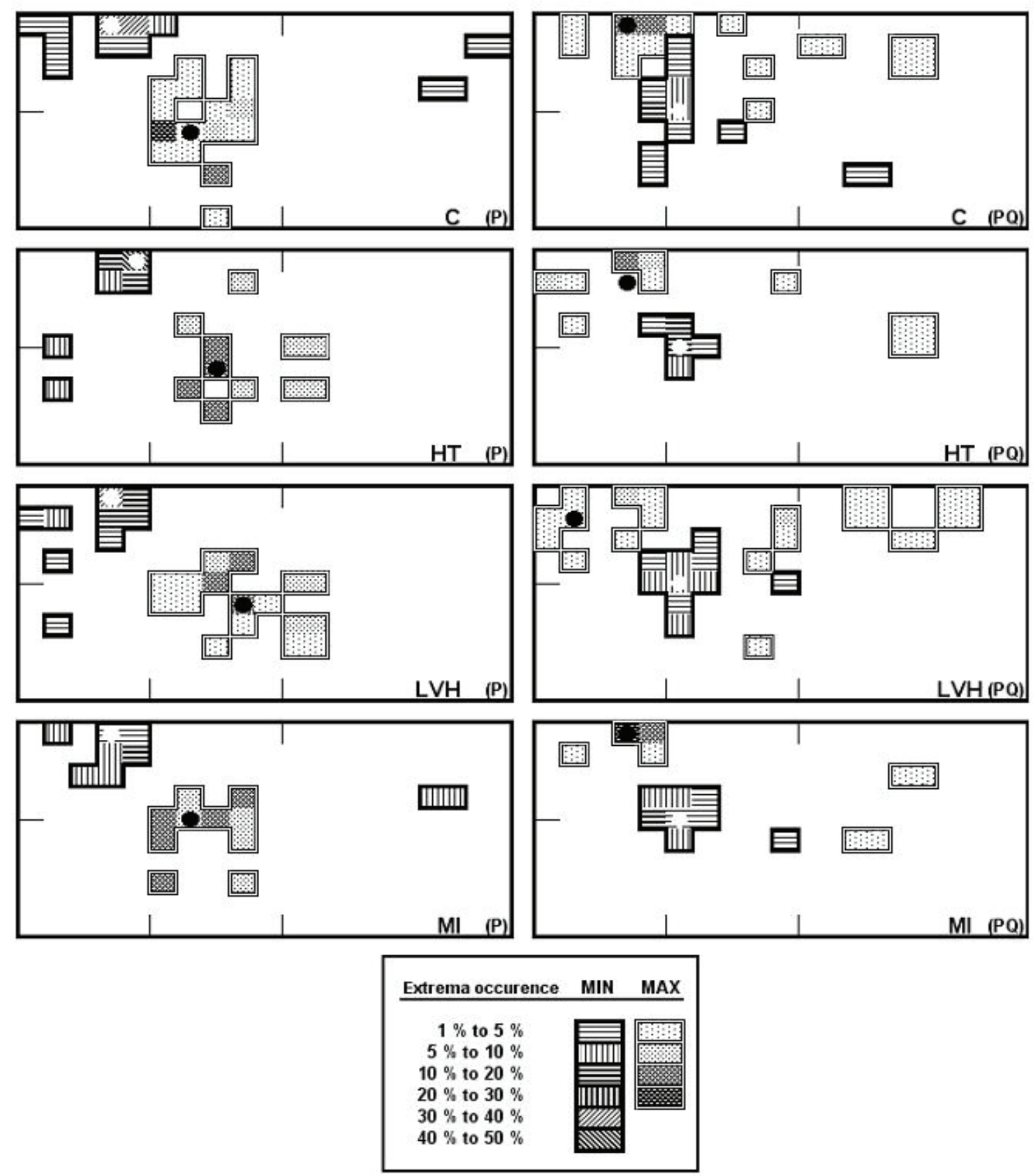

Fig. 2. The positions of the $P$ wave (left column) and the $P Q$ segment (right column) extrema in individual maps. The short vertical lines in every map depict the positions of the sternum and the left mid-axillary line, respectively. The short horizontal line depicts the approximate position of the $5^{\text {th }}$ intercostal space. The white circles display the median position of the minimum, the black circles the median position of the maximum.

hypertrophied atria, to the increased pressure in their cavities, to hypertension or the existence of atrial substrate for atrial fibrillation mainly in patients with ventricular myocardial infarction even in the case with no atrial involvement (Miyauchu et al. 2003, Vranka et al. 2007).

Every mapping procedure has some specific advantages (Kittnar and Mlček 2010). Isointegral maps can comprise phenomena lasting for longer time as they summarize in one map both the amplitudes and the time. Consequently, isointegral maps may suppress the noise in low amplitude signals as are the $\mathrm{P}$ wave and mainly the PQ segment.

There are no papers dealing with isointegral maps of the PQ segment, therefore, we can compare them only with isopotential maps. In all published papers, the 
locations of all maxima and some minima were found outside the regions examined by the standard chest leads. Amplitudes were much lower than in the corresponding $P$ wave maps and the reversed polarity between the $\mathrm{P}$ wave and the PQ segment was described (Ihara et al. 2006, Kornreich et al. 1989, Mirvis 1980, Spach et al. 1979, Stilli et al. 1983). The PQ segment was never isoelectric as well as in our study. The description of potential distributions was only qualitative; no quantification of the reversed polarity such as correlation coefficients in this study was published yet.

Better correlation between the $\mathrm{P}$ wave and the PQ segment maps in the patients with arterial hypertension and left ventricular hypertrophy as compared to the controls was found. There was increased blood pressure in both groups of patients. To overcome it, the atria have to contract more strongly. As each myocardial contraction is preceded by its activation, this situation could probably produce a better coordinated activation with less "noise" followed by a better coordinated repolarisation (smooth and not splitting wave fronts). The worst correlation in the MI group could be probably ascribed to the atrial substrate for atrial fibrillation that may influence both the atrial activation and recovery (Aldhoon et al. 2010, Vranka et al. 2007). Specialized studies are needed to confirm these assumptions.

The published data as well as our results suggest that the repolarisation spreads through the atrial walls in approximately the same order, as the depolarisation does. This is in agreement with experimental data demonstrating that the atrial regions that depolarize as first also repolarise as first (Spach et al. 1969).

To conclude, we found that the opposite polarity during the PQ segment to the $\mathrm{P}$ wave can be recorded when using body surface potential mapping - isointegral maps - and that these isointegral maps differ between the studied groups of patients. These differences are probably connected with diverse behavior of the activation and recovery wave fronts due to several diagnoses. They are connected with prolonged $\mathrm{P}$ waves in patients.

We confirmed again that the extrema (potential amplitudes) occur in areas not examined by the standard electrocardiographic chest leads. This finding and the fact that the PQ segment is not isoelectric should be considered for diagnostic purposes.

\section{Conflict of Interest}

There is no conflict of interest.

\section{Acknowledgements}

This study was partially supported by grant KEGA 004UK-4/2011 from the Ministry of Education, Science, Research and Sport, Slovak Republic. These results were partially presented at the $4^{\text {th }}$ Young Biomedical Engineers and Researchers Conference - YBERC 2010, held in Košice (Slovak Republic) on July 1-3, 2010.

\section{References}

ALDHOON B, MELENOVSKÝ V, PEICHL P, KAUTZNER J: New insights into mechanisms of atrial fibrillation. Physiol Res 59: 1-12, 2010.

BARR RC, SPACH MS, HERMAN-GIDDENS GS: Selection of the number and positions of measuring locations for electrocardiography. IEEE Trans Biomed Eng 18: 125-138, 1971.

BULAS J, MURÍN J, KOZLÍKOVÁ K: Echocardiographic characteristics of left ventricular hypertrophy. (in Slovak) Kardiológia/Cardiology 7: 92-98, 1998.

CAGÁŇ S, HULÍN I: Electrocardiography. (in Slovak) Osveta, Martin, 1981.

IHARA Z, VAN OOSTEROM A, HOEKEMA R: Atrial repolarization as observable during the PQ interval. J Electrocardiol 36: 290-297, 2006.

KITTNAR O, MLČEK M: Analysis of the electrical heart field. Physiol Res 59 (Suppl 1): S19-S24, 2010.

KORNREICH F, MONTAGUE TJ, RAUTAHARJU PM, KAVADIAS M, HORACEK MB, TACCARDI B: Diagnostic body surface potential map patterns in left ventricular hypertrophy during PQRST. Am J Cardiol 63: 610-617, 1989.

KOZLÍKOVÁ K: Surface integral maps, their characteristics and methods of quantitative analysis. (in Slovak) Brat Lek Listy 91: 815-823, 1990.

KOZLÍKOVÁ K: P wave body surface isointegral maps in children and in young adults. Physiol Res 56 (Suppl 1): S123-S128, 2007. 
KOZLÍKOVÁ K, MARTINKA J: The Essentials of Biomedical Measurement Processing II. (in Slovak) Asklepios, Bratislava, 2009.

LANG RM, BIERIG M, DEVEREUX RB, FLACHSKAMPF FA, FOSTER E, PELLIKKA PA, PICARD MH, ROMAN MJ, SEWARD J, SHANEWISE JS, SOLOMON SD, SPENCER KT, SUTTON MS, STEWART WJ: Recommendations for chamber quantification: a report from the American Society of Echocardiography's Guidelines and Standards Committee and the Chamber Quantification Writing Group, developed in conjunction with the European Association of Echocardiography, a branch of the European Society of Cardiology. J Am Soc Echocardiogr 18: 1440-1463, 2005.

MACFARLANE PW, VEITCH LAWRIE TD (eds): Comprehensive Electrocardiology. Theory and Practice. Pergamon Press, New York, 1989.

MANCIA G, DE BACKER G, DOMINICZAK A, CIFKOVA R, FAGARD R, GERMANO G, GRASSI G, HEAGERTY AM, KJELDSEN SE, LAURENT S, NARKIEWICZ K, RUILOPE L, RYNKIEWICZ A, SCHMIEDER RE, STRUIJKER BOUDIER HA, ZANCHETTI A, ET AL.: 2007 Guidelines for the management of arterial hypertension. The Task Force for the Management of Arterial Hypertension of the European Society of Hypertension (ESH) and of the European Society of Cardiology (ESC). Eur Heart $J \mathbf{2 8}$ : 1462-1536, 2007.

MIRVIS DM: Body surface distribution of electrical potential during atrial depolarization and repolarization. Circulation 62: 167-173, 1980.

MIRVIS DM: Electrocardiography. A Physiologic Approach. Mosby, St. Louis, 1993.

MIYAUCHI Y, ZHOU S, OKUYAMA Y, MIYAUCHI M, HAYASHI H, HAMABE A, FISHBEIN MC, MANDEL WJ, CHEN LS, CHEN P-S, KARAGUEUZIAN HS: Altered atrial electrical restitution and heterogeneous sympathetic hyperinnervation in hearts with chronic left ventricular myocardial infarction. Implications for atrial fibrillation. Circulation 108: 360-366, 2003.

MOSTELLER RD: Simplified calculation of body-surface area. N Engl J Med 317: 1098, 1987.

ROSÍK V, TYŠLER M, TURZOVÁ M: Portable device of for ECG mapping. In: Proceedings of International Conference of Measurement. I FROLLO, A PLAČKOVÁ (eds), SAV, Bratislava, 1997, pp. 367-370.

SPACH MS, BARR RC, BENSON W, WALSTON AII, WARREN RB, EDWARDS SB: Isopotential body surface mapping in subjects of all ages: emphasis on low-level potentials with analysis of the method. Circulation 59: 822-836, 1979.

SPACH MS, KING TD, BARR RC, BOAZ DE, MORROW MN, HERMAN-GIDDENS S: Electrical potential distribution surrounding the atria during depolarization and repolarization in the dog. Circ Res 24: 857-873, 1969.

Statgraphics ${ }^{\circledR}$ PLUS, version 3 for Windows. User manual. Manugistics, Inc., Rockville, 1997, 738 pp.

STILLI D, MUSSO E, BARONE P, CIARLINI P, GUSPINI A, MACCHI E, REGOLIOSI G, TACCARDI B: Description of averaged maps relating to the P, P-Q and ST intervals in normal adults. In: Advances in Body Surface Potential Mapping. K YAMADA, K HARUMI, T MUSHA (eds), University of Nagoya Press, Nagoya, 1983, pp. 195-200.

TAKALA P, HÄNNINEN H, MONTONEN J, MÄKIJÄRVI M, NENONEN J, OIKARINEN L, SIMELIUS K, TOIVONEN L, KATILA T: Magnetocardiographic and electrocardiographic exercise mapping in healthy subjects. Ann Biomed Eng 29: 501-509, 2001.

VESTERINEN P, HÄNNINEN H, KARVONEN M, LAUERMA K, HOLMSTRÖM M, MÄKIJÄRVI M, VÄÄNÄNEN H, NENONEN J, KATILA T, TOIVONEN L: Temporal analysis of the depolarization wave of healed myocardial infarction in body surface potential mapping. Ann Noninvasive Electrocardiol 9: 234-242, 2004.

VRANKA I, GAŠPAR L', DUKÁT A: Standard and high-resolution electrocardiography of the $\mathrm{P}$ wave in patients at risk for atrial fibrillation. (in Slovak) Kardiológia/Cardiology 16: 15-21, 2007.

YAMAKI M, IKEDA K, HONMA K, KIRIYAMA N, TONO-OKA I, TSUIKI K, YASUI S: Diagnosis of right ventricular involvement in chronic inferior myocardial infarction by means of body surface QRS changes. Circulation 6: 1283-1290, 1988. 